\title{
ERJ
}

Engineering Research Journal

Faculty of Engineering

Minoufiya University

\section{THE EFFECT OF SOLID-LIQUID MIXTURE ON CAVITATION CHARACTERISTICS OF A CENTRIFUGAL PUMP}

\author{
S. M. Selim ${ }^{(1)}$, M. A. El-kadi ${ }^{(2)}$, M. A. Younes ${ }^{(3)}$, \\ M. A. Hosien ${ }^{(4)}$, and I. R. Teaima ${ }^{(5)}$ \\ 1.2,4) Department of Mechanical Engineering, Faculty of Engineering, Shebin El-Kom \\ Minoufiya University, Egypt. \\ ${ }^{3.5)}$ Mechanical and Electrical Research Institute (MERI), National Water Research \\ Center (NWRC), Delta Barrage, Egypt.
}

\begin{abstract}
The objective of the present study is to present new experimental results of the effect of solids on the cavitation inception of centrifugal pump under varying suction conditions. The experiments were conducted using sand slurry with different solids size at different concentration and different pump speed. Measurements of power consumption, flow rate, total head developed by the pump were made in order to obtain the effect of solids on the cavitation characteristics of centrifugal pumps handling slurries. The results show that the cavitation inception has been accelerated with increasing solid concentration, and pump speed while the particle size has little effect on cavitation inception.

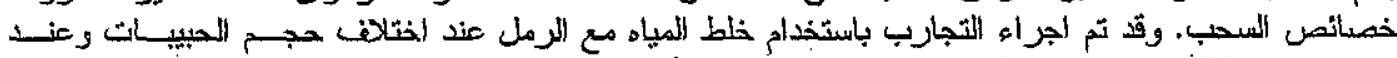

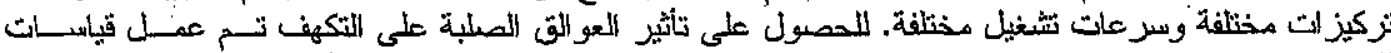

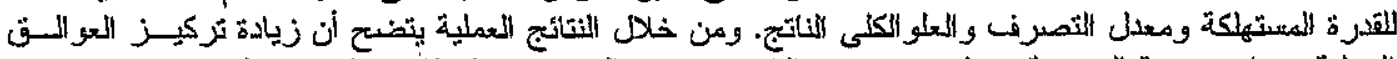

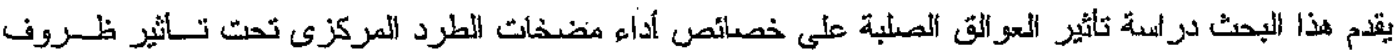

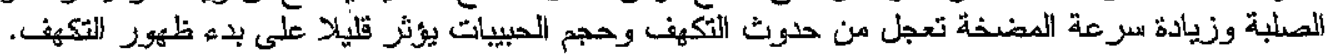

Keywords: Centrifugal pump - Suction conditions - Solids concentration - Cavitation inception.

\section{INTRODUCTION}

Centrifugal slurry pumps are being used extensively in pipeline transportation systems because of short and medium distance transportation of homogenous and hetrogenous mixtures of solid materials by pipelines. The pump characteristics play a role in the reliability of the transportation system. These purnps have been developed by suitably modifying the design of conventional centrifugal pumps to ensure proper flow of solid liquid mixtures and to minimize erosive wear. To avoid cavitation in the pumping liquids the pressure at any point in the suction line must never be reduced to the saturated vapor pressure $\left(\mathrm{P}_{\mathrm{v}}\right)$ of the liquid. Pressure drops occur due to losses in suction pipe and local flow acceleration at the impeller inlet. The available energy that can be utilized to get the liquid through the suction piping and suction water way of the pump into impeller is thus the local suction head reduced to the vapor pressure of the liquid at the pumping temperature. The resulting available head measured at the suction opening of the pump represents, net positive suction head available, commonly indicated by NPSH

$$
N P S H A=\frac{P_{a p n}}{\rho g}-\frac{P_{V}}{\rho g} \pm Z_{0}-h_{f}
$$

The NPSHR, is the net positive suction head required by the pump and depends on pump design. It is obtained by the centrifugal pump test on water and represents the minimum margin between the suction head and vapor pressure required for proper pump operation. In accordance with current practice, the NPSHR data on pump performance curves represent values at which the total head of a single stage pump will be reduced by $3 \%$ of its full published value. Both NPSHA and NPSHR values change with variation in the pump flow rate at a given speed.

Roundnev [1] studied the slurry pump. suction performance considerations. He showed that, the net positive suction head required by the slurry pump can not be assumed to be the same as that on water and additional corrections are needed. Mashin [2] conducted laboratory experiments on a 5 inch end suction slurry pump with $330 \mathrm{~mm}$ impeller, handling sand slurry of 1.15 specific gravity and mean particle diameter of $1 \mathrm{~mm}$. He concluded that the NPSH required by centrifugal pump on this type of slurries has the same value as that for water, with no additional correction required for solids. It means that cavitation in the pump handling slurry starts at higher suction pressure than on water. Herbich and Cooper [3] came to the same conclusion by testing dredge pumps of settling slurries. Kirillov and Smoilovskaya [4] studied the suction performance of a 5 inch end suction slurry pump tested in laboratory conditions handling sand and gravel slurries with 
various sizes of solids. They concluded that the net positive suction head required by centrifugal pump has the same value as that for water, with no additional correction required. Mogilevsky and Smoilovskaya [5] conducted test work on a 4 inch side inlet slurry pump with several impellers, including closed type impellers with 4 and 6 vanes and channel-type two-vane impeller. They concluded that slurry pump suction performance pumping heavy media of magnetite should also be different from that on water. Roundnev [6] studied the effect of solids on NPSH when pumping slurry. He concluded that the net positive suction head required by the pump can not be a summed the same as that on water. Thus, different correction methods need to be employed. Addie et al. [7] studied the cavitation characteristics of centrifugal pumps handling slurries. They concluded that the net positive suction head required by 20 inch slurry pump increased 1.5 times compared to water when pumping phosphate slurry. Investigations reported in the literature about the centrifugal pump characteristics under cavitation conditions pumping slurries are limited. There is also a conflict information about the effect of cavitation on centrifugal purmp performance when handling slurries. So the objective of this study is to investigate the effects of solids concentration, particle size, and pump speed on the centrifugal pump characteristics when the pump is working. under cavitation condition.

\section{EXPERIMENTAL WORK}

\subsection{Experimental Apparatus and Instrumentation}

In the present study experiments were conducted to determine the individual effects of particle size, pump speed and concentration of solids on the centrifugal pump performance when the pump working under cavitation conditions.

The experimental data were obtained by conducting experiments using a specially designed and fabricated experimental facility. The schematic view of the test rig is shown in Fig.1. A typical impeller of centrifugal pump having specifications $d_{1}=54 \mathrm{~mm}$, $\mathrm{d}_{2}=175 \mathrm{~mm}, \mathrm{~b}_{1}=10.5 \mathrm{~mm}, \mathrm{~b}_{2}=5 \mathrm{~mm}, \beta_{1}=21.5^{\circ}, \beta_{2}=28^{\circ}$ and $z=6$ (backward curved) was used in the experiments. For more details about the test rig and experiments please refer to Ref. (8).

\subsection{Test Method}

In order to study the effect of the suspended solids on the centrifugal pump characteristics under cavitation conditions, testes were conducted with three sorts of narrowly graded sands with specific gravity 2.52 , (fine sand, medium sand, and coarse sand). The physical properties of the materials are shown in Table1. Measurements were made with six different concentrations of each solid material for the operating speed of the pump. The mixture was kept in circulation for approximately 15 minutes to assure a complete mixing before starting any measurements.

The delivery valve was opened while the pump in operation at a constant rotating speeds. The power input to the motor, the flow rate, and the suction and delivery pressures were recorded. The density of the mixture ( $\mathrm{pm}$ ) was determined from the value of solid concentration. The measurements were repeated for various settings of the delivery valve, suction valve various concentrations of solid particles and various types of materials. The experiments conducted under varying suction lift through the suction valve, constant speed and constant flow rate.

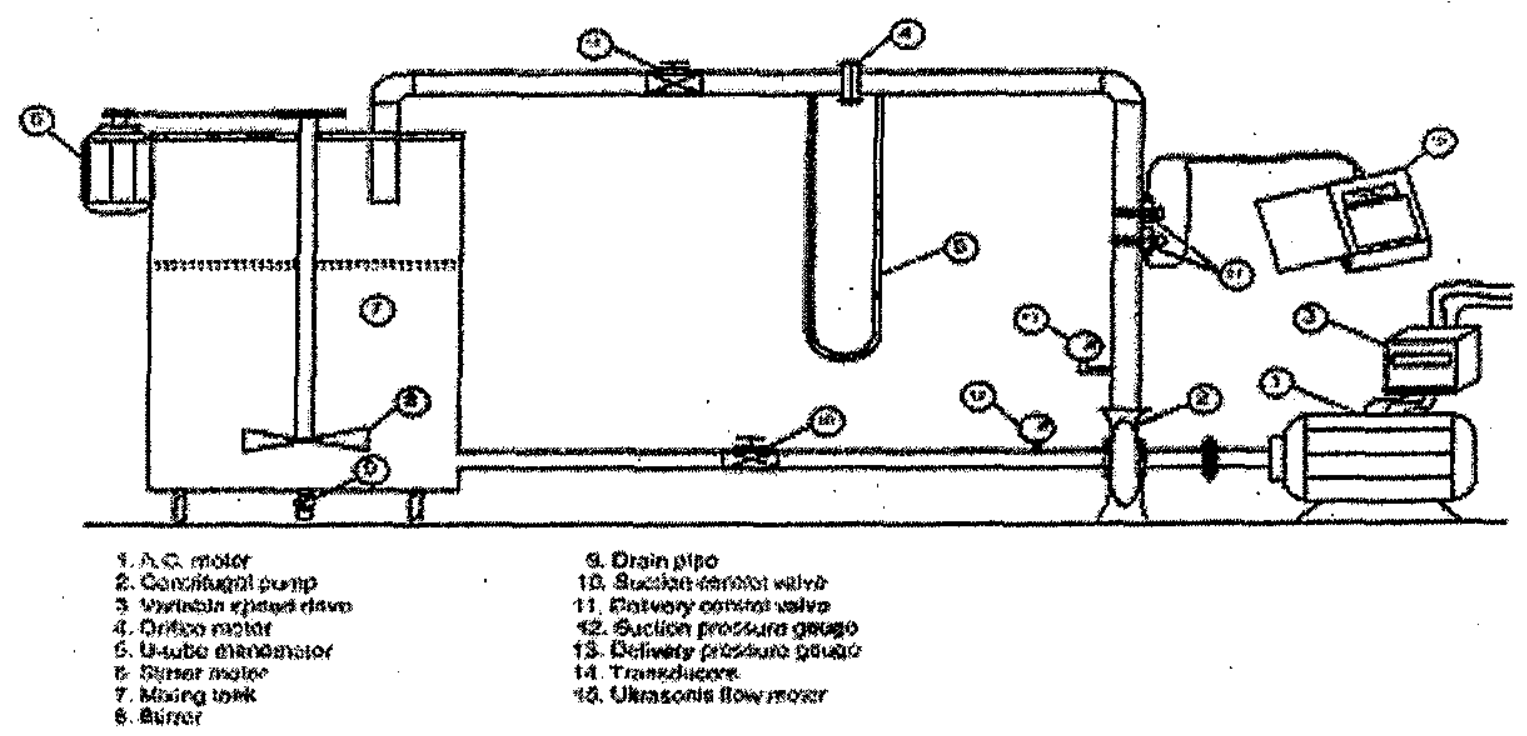

Fig.1 Schematic view of the experimental set-up. 
Table1 Physical properties of the material used.

\begin{tabular}{|l|c|c|c|}
\hline Materials & $\begin{array}{c}\text { Specific gravity } \\
\mathrm{S}(-)\end{array}$ & $\begin{array}{c}\text { Mass median } \\
\text { diameter(mm) } \mathrm{d}_{50}\end{array}$ & $\begin{array}{c}\text { Weighted mean } \\
\text { diameter }(\mathrm{mm}) \mathrm{d}_{\mathrm{w}}\end{array}$ \\
\hline Fine to medium sand & 2.52 & 0.152 & 0.152 \\
\hline Medium sand & 2.52 & 0.203 & 0.206 \\
\hline Coarse to medium sand & 2.52 & 0.341 & 0.348 \\
\hline
\end{tabular}

\section{EXPERIMENTAL RESULTS}

\subsection{Effect of Flow Rate on Cavitation Characterístics}

Figures (2-4) show the variation of NPSH with the pump head at various values of the normalized flow rates for constant values of solids concentration and rotational speed for all types of slurries. The flow rate was varied from $1 \mathrm{lit} / \mathrm{sec}$ to $9 \mathrm{lit} / \mathrm{sec}$. Generally these figures show that the maximum available net positive suction head value is dependent upon the flow rate. The observed trend is that the value of the maximum available net positive suction head increases with decreasing the flow rate. This can be attributed to the increase of the flow velocity with flow rate and decrease of the suction pressure with flow rate. The combination of these two parameters should cause an increase of maximum available net positive suction head with decreasing flow rate. Therefore, it is evident that with increasing flow rate the decrease in suction pressure is large than the increase in velocity head of the flow which is proportional to the square of the velocity. Figures (24) indicate, for all operating conditions tested, that the head rise across the pump is maintained nearly at constant value from the maximum available net positive suction head down to the inception condition (NPSHi). As the NPSH is decreased down to near the breakdown of the pump head, the head rise remains nearly unchanged, except for lower flow rate, there is a tendency for the head rise across the pump to decrease as the NPSH decreases for developed cavitation condition. Figures (5-7) illustrate that the efficiency drops gradually over a wide range of the NPSH. The NPSH at which the drop start is dependent upon the flow rate. It decreases with decreasing the flow rate.

\subsection{Effect of Solid Concentration on Cavitation Characteristics}

Cavitation characteristics tests on slurries are difficult to conduct, especially at higher concentrations and larger size solids, so, a certain scatter of points can be expected.

The experimental observations on the pump cavitation characteristics with different solid-liquid mixtures at operating speed of $3000 \mathrm{rpm}$ are presented in Figures (8-10). These figures show the variation of NPSH with head at various values of solid concentrations and constant values of flow rate and rotational speed for all types of slurries. The solid concentration varied from 5 to 32 percent by weight for all types of slurries.

Generally these Figures show that the maximum available net positive suction head value is dependent upon the solids concentration. The cause of increasing the maximum available net positive suction head with decreasing the solid concentration can be attributed to the increase of the mixture density with increasing solids concentration. Figures (8-10) illustrate that the pump head decreases with increasing solids concentration. This is mainly due to the hydraulic losses due to slip between the solid particles and the liquid.

Figures (11-13) represent the variation of the NPSH with efficiency of the pump at various values of the solid concentration at constant value of flow rate and rotational speed for all type of slurry. These figures indicate that the pump efficiency decreases with increasing the solid concentration. It can also be seen that at low solids concentration the pump efficiency remains constant for longer time than that at high concentrations. Figure (14) shows a comparison between measured experimental results of pump head with the published results obtained by Roundnev [1] taken into account the variation of pump head with NPSH and mixture density for medium sand sluriy $\left(\mathrm{d}_{50}=0.203 \mathrm{~mm}\right)$. Roundnev [1] used $5^{\prime \prime}$ end suction slurry pump for water, sand $\left(\mathrm{d}_{50}=0.2 \mathrm{~mm}\right)$ at best efficiency point. The comparison was carried out at best efficiency point, and its show the same trend. The discrepancy of the results may be due to the difference of pump size and sand specific gravity.

\subsection{Effect of Rotational Speed on the Cavitation Characteristics}

This section presents the effect of pump rotational speed on pump cavitâtion performance at various flow rate and different solid concentration for all types of slurries used. The effect of pump rotational speed on variation of NPSH with purmp head is shown in Figures (15-17). These figures show that the pump head increases with the increase of the pump rotational speed for all values of flow rate and solids concentration. The figures show also that at 
lower rotational speeds the pump head remains constant for longer time than that at higher rotational speeds. This is mainly due to the increase in the shock losses which increase with increasing the rotational speed. It can be seen that the pump head decreases steeply at high rotational speeds and this may be due to the recirculatory flow at the inlet of the pump, where the incidence angle becomes greater than the blade angle.

Generally these Figures show that the maximum available NPSH value increases with increasing of rotational speed and the NPSH at which the drop in head starts increases with increasing the rotational speed. Figures (18-20), show the effect of the pump rotational speed on the variation of pump efficiency versus the NPSH at constant flow rate and constant solids concentration for all types of slurries. These Figures show that the pump efficiency increases with increasing the pump rotational speed. This is mainly due to increasing the flow rate and the pump head, which are proportional to pump efficiency. Generally, it can be seen from these Figures that the efficiency attained nearly at constant value from the maximum NPSH down to the point at which the breakdown occurred. The results showed that the breakdown cavitation at high pump rotational speed occurred earlier than that at low pump rotational speed, and the reason of this is the increasing of losses at high pump rotational speed which speeds up the cavitation occurrence.

\subsection{Visual Incipient Net Positive Suction Head}

In this section the major goal is to investigate experimentally the effect of flow rate, punp rotational speed, solid concentration and particle size distribution on the visual incipient net positive suction head $\left(\mathrm{NPSH}_{\mathrm{i}}\right)$. The visual inception cavitation refers to the first appearance of a limited cavitation zone at the leading edge of the blade of the pump. The inception condition was observed by stroboscope and by maintaining a constant flow rate while reducing the suction pressure. If the visual $\mathrm{NPSH}_{\mathrm{i}}$ measurements can be used to develop possible relationships with the NPSH corresponding to $3 \%$ drop in head which the pump designers consider as criterion of cavitation inception. It will be very convenient for design and practical purposes.

\subsubsection{Effect of flow rate on $\mathrm{NPSH}_{\mathbf{i}}$}

A study of the effect of flow rate on the visual inception net positive suction head $\left(\mathrm{NPSH}_{\mathrm{i}}\right)$ was conducted over a wide range of solid concentration and rotational speed for all type of solids. The results are shown in Figures (21-23), which are summarizing an extensive series of testes. These Figures indicate that for all test conditions the $\mathrm{NPSH}_{i}$ depends strongly on the flow rate. The flow rate ratios were ranged from 0.12 to 1.1 . The general trends of the
$\mathrm{NPSH}_{\mathrm{i}}$ versus flow rate ratio curves are that the $\mathrm{NPSH}_{\mathrm{i}}$ decreases with increasing the flow rate reaching minimum then increases with increasing the flow rate. At low flow rate ratio the mixture within a vortex core is subjected to low pressure area for longer period. Hence, this tends to entrain nuclei within their low pressure core where gaseous cavitation occurs. It is well known that cavitation occurs when the local pressure in the flow is less than the critical value $P_{c}$. gaseous cavitation is induced by a local drop in pressure below the saturation level for a given concentration of non-condensable gas in water. For typical size nuclei in a saturated liquid, the critical pressure is greater than the vapor. pressure. Bubble growth by this mechanism is relatively slow process hence, gaseous cavitation can only occurs when a given cavitation nucleus is exposed to a pressure below the critical value for a relatively long period of times as case of low flow rates. In addition there is also a possibility at low flow rate ratios that the reverse flow associated with inlet pre-rotation would constrict the effective inlet flow rate area; thus accelerating the main flow and dropping the inlet pressure. At higher flow rate ratios the local pressure difference generated by vortices and the strength of vortices will be varied, as the wake region is reduced. In addition, at higher flow rate ratio the time available for nuclei to growth is shorter. To initiate cavitation a nucleus must growth to a critical size in less time than the time spent by the nucleus in the minimum pressure region. It is obvious that, if the pressure time for bubble growth is short the critical pressure for growth can be expected to be less than the vapor cavitation. Moreover, increasing the flow rate ratio will result in an increase in the meridinal velocity at inlet of the blade.

\subsubsection{Effect of solid concentration and rotational speed on NPSH$_{\mathbf{i}}$}

In this section the effects of changing the incipient net positive suction head with solid concentration visually at different flow rate and various rotational speeds are presented The testes were conducted over a wide range of solid concentrations, flow rate and rotational speeds. The solid concentration was varied from 5 to 32 percent (by weight) for three sorts of sand and flow rate ratio varied from 0.12 to 1.1 . The results are shown in Figures (24-26). These Figures indicate that for all testes the $\mathrm{NPSH}_{\mathrm{i}}$ depends strongly on the solid concentration. The general trends of the NPSHi versus the solid concentration curves are presented at a given flow rate ratio and varied rotational speed. The results showed that the NPSHi increases with increasing the solid concentration for all types of slurry and rotational speed. 


\subsubsection{Effect of particle size on the $\mathrm{NPSH}_{\mathrm{i}}$}

A study of the effect of particle size on the inception net positive suction head (NPSHi) versus solid concentration was conducted at various flow rate and different pump speed. The results are shown in Figures (27-29). From these Figures it is shown that the variation of particles size has a little effect on cavitation inception. This means that the large size particles do the same rupture in flow as many small particle of the same concentration.

3.5. Empirical Correlation for the Head Reduction Factor, $\mathbf{R}_{\mathrm{h}}$ of Centrifugal Pumps when Handling Slurries

It is now well established that the performance of centrifugal pumps with slurries is different from that with clear water and also by the presence of solids in the carrier liquid. The magnitude of the reduction in the pump performance is mainly function of weighted or volumetric concentration of solids in the mixture, physical properties of solids like their specific gravity, and particle size. In analyzing the results of the pump performance the ratios between $R_{h}, C_{w}, d_{50}$ and $S$ were examined and the following relationship equation can be expressed:

$$
R_{h}=20.9589 C_{w}^{0.88253}(S-1)^{-6.3397} d_{50}^{0.69374}
$$

To gain an insight into the applicability of present correlation a comparison was made between the measured and predicted values of head reduction factor $R_{h}$. This is shown in Figure (30). It is observed that the errors in the prediction of $R_{h}$ are random and lie within the \pm 10 percent band. This spread appears to be reasonable considering the wide range of parameters investigated.

\section{CONCLUSIONS}

From the present experimental investigations on the centrifugal pump characteristics with different slurries, when working under cavitation conditions the following conclusions can be obtained:

1. The NPSHi increases with increasing solids concentration and pump speed.

2. The NPSHi is affected by flow rate, it decreases with increasing flow rate and reaching a minimum and then increased with increasing flow rate.

3. The head and efficiency of the pump with NPSH are decreased with increasing the solid concentration and particle size.

4. The particle size has little effect on cavitation inception.

5. A new correlation has been developed in order to predict head reductions factor, $\mathrm{R}_{\mathrm{h}}$ of centrifugal pumps when handling slurries. The proposed correlation takes into account the individual effects of particle size, specific gravity and concentration of solids on pump performance.

$$
R_{h}=20.9589 C_{1 \%}^{0.88253}(S-1)^{-6.3397} d_{50}^{0.69374}
$$

\section{REFERENCES}

[1] Roundnev, A.S., 2004, "Slurry Pump Suction Performance Consideration," Proc. $16^{\text {th }}$ Intl. Conference on Hydrotransport, BHR Group, Santiago, Chile, pp.137-150.

[2] Mashin, A.N., 1954, "Cavitation Performance of Dredge Pumps on Water and Slurry," Technical Information Bullentin No 5, VIGM, Moscow.

[3] Herbich, J.B., and Cooper, R.L., 1971, "The Effect of Solid-Water Mixtures on Cavitation Characteristics of Dredge Pumps," Proc. Fourth World Dredging Conference, New Orleans, LA.

[4] Kirillov, V.V., and Smoilovskaya, L.A., 1984, "Cavitation Performance of Slurry Pumps Handling Mixtures with Various Size of Solids," Advancing Technology of Minerals Excavation and Processing, Moscow, VNIIPLstromyrjo, pp.141-144.

[5] Mogilevsky, Y.N., and Smoilovskaya, L.A., 1972,"Suction Performance of Centrifugal Pump when Handling Magnetite Slurry," HydroMechanization of Mining, Construction, Melioration and Transport Processes, Proceedings, Moscow.

[6] Roudnev, A. S., 2003, "Understanding NPSH when Pumping Slurry", Part 1, Weir Slurry Pipeline, Volume 2, pp.5-7, Weir Slurry North America.

[7] Addie, G.R., Wilson, K.C., and Sellgren, A:, 1999, "Suction Performance of Centrifugal Pumps and its Effect on Coast of Slurry Transport,". Hydrotransport 14, pp.515-526.

[8] Selim, S.M., El-Kadi, M.A., Younes, M.A., Hosien, M.A., and Teaima, I.R., 2007, "Effect of Solid Concentration on a Centrifugal Pump Performance," Engineering Research Journal, Minoufiya University, Vol.30, No.1, pp.67-76.

\section{NOMENCLATURE}

BEP best efficiency point

$b_{1} \quad$ blade height at inlet $(\mathrm{mm})$

$\mathrm{b}_{2}$ blade height at exit (mm)

$\mathrm{C}_{\mathrm{w}} \quad$ solid concentration by weight (percent)

$\mathrm{d}_{\mathrm{l}} \quad$ blade diameter at inlet $(\mathrm{mm})$

$\mathrm{d}_{2} \quad$ blade diameter at exit $(\mathrm{mm})$

$\mathrm{d}_{50} \quad$ mean average particle diameter $(\mathrm{mm})$

$\mathrm{d}_{\mathrm{w}} \quad$ weighted mean diameter $(\mathrm{mm})$

$\mathrm{NPSH}_{\mathrm{A}}$ net positive suction head available (m)

$\mathrm{NPSH}_{\mathrm{R}}$ net positive suction head requirement (m)

$\mathrm{S} \quad$ solid specific gravity

$R_{h}$. head reduction factor (percent) 
S. M. Selim, M. A. El-kadi, M. A. Younes, M. A. Hosien, and I. R. Teaima, "The Effect of Solid-Liquid ... "

$\mathrm{z} \quad$ number of blades

$\beta_{1} \quad$ inlet blade angle (degrees)

$\beta_{2} \quad$ exit blade angle (degrees)

$\rho_{111}=100 /\left[\left(C_{w} / \rho_{s}\right)+\left(\left(100-C_{w}\right) / \rho_{L}\right)\right]$

(density of slurry mixture). $\left(\mathrm{kg} / \mathrm{m}^{3}\right)$

$\rho_{\mathrm{s}} \quad$ density of the solid phase $\left(\mathrm{kg} / \mathrm{m}^{3}\right)$

$\rho_{\mathrm{L}} \quad$ density of the liquid phase $\left(\mathrm{kg} / \mathrm{m}^{3}\right)$

$P_{\text {atm }} \quad$ atmospheric pressure (Kpa)

$\mathrm{G} \quad$ acceleration due to gravity $\left(\mathrm{m} / \mathrm{s}^{2}\right)$

$\mathrm{Z}_{0} \quad$ elevation head (m)

$\mathrm{h}_{\mathrm{f}} \quad$ friction head losses (m)

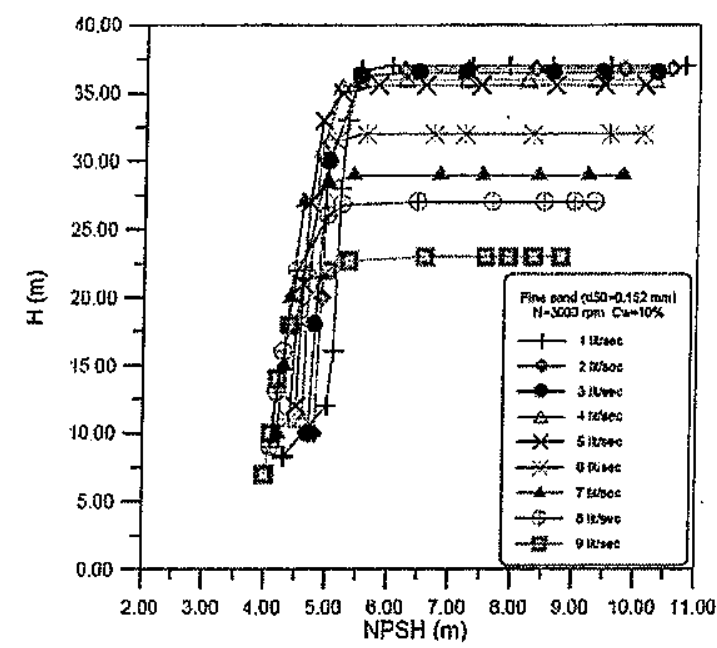

Fig. 2 Variation of NPSH with pump head for fine sand $\left(\mathrm{d}_{50}=0.152 \mathrm{~mm}\right)$ at constant speed $(\mathrm{N}=3000$ $\mathrm{rpm}$ ) and concentration ( $\mathrm{Cw}=10 \%$ ) at different flow rate.

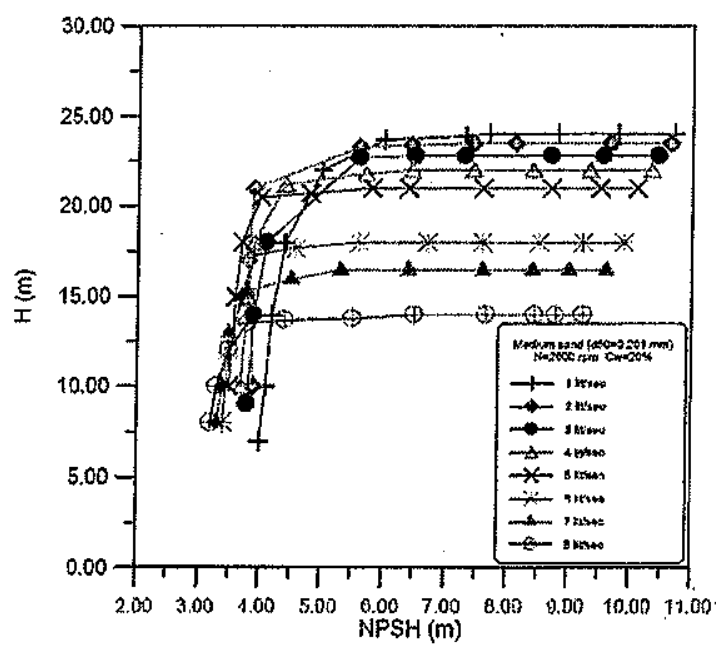

Fig.3 Variation of NPSH with pump head for medium sand $\left(\mathrm{d}_{50}=0.203 \mathrm{~mm}\right)$ at constant speed $(\mathrm{N}=2600 \mathrm{rpm})$ and concentration $(\mathrm{CW}=10 \%)$ at different flow rate.

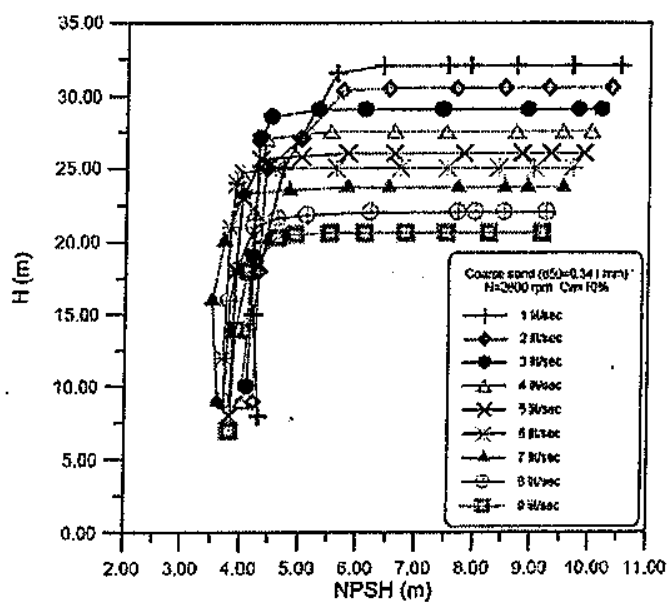

Fig.4 Variation of NPSH with pump head for coarse sand $\left(\mathrm{d}_{50}=0.341 \mathrm{~mm}\right)$ at constant speed $(\mathrm{N}=2800$ $\mathrm{rpm})$ and concentration $(\mathrm{Cw}=10 \%)$ at different flow rate.

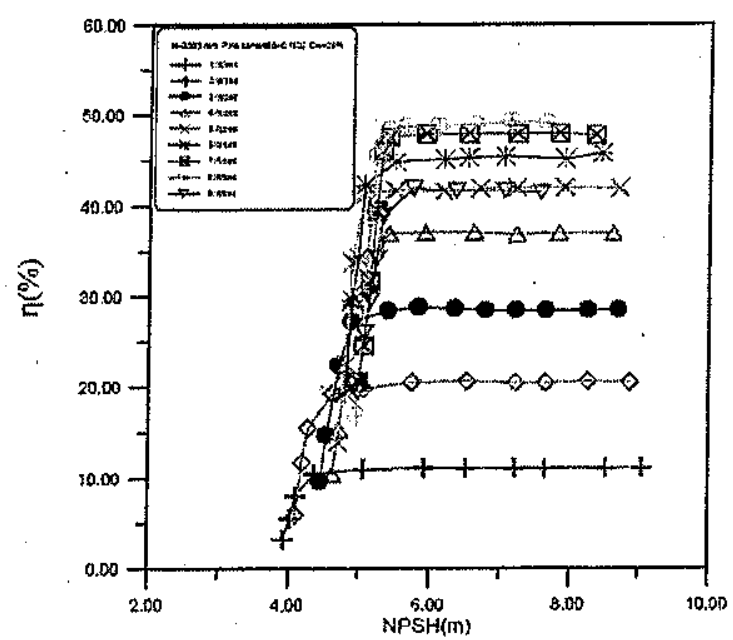

Fig.5 Variation of NPSH with pump efficiency for fine sand $(\mathrm{d} 50=0.152 \mathrm{~mm})(\mathrm{N}=2600 \mathrm{rpm})$ and $\mathrm{C}_{\mathrm{w}}=25 \%$.

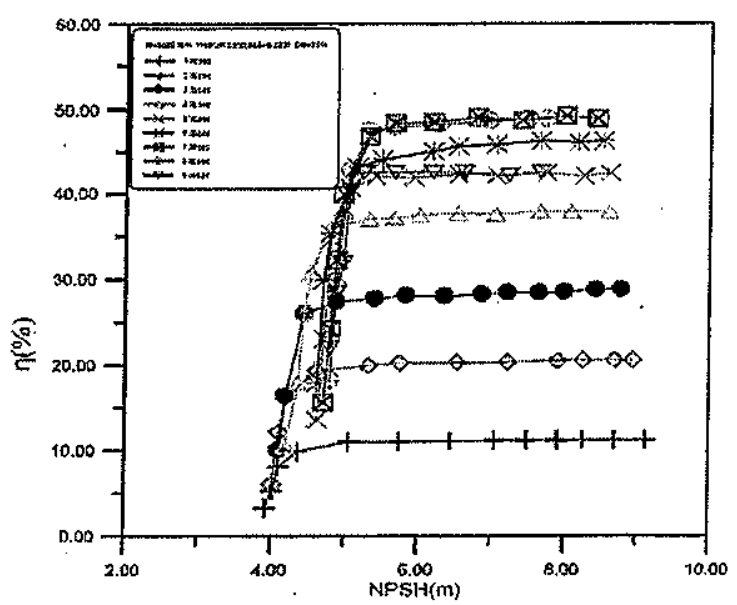

Fig.6 Variation of NPSH with pump efficiency for medium sand $(\mathrm{d} 50=0.203 \mathrm{~mm})(\mathrm{N}=2800 \mathrm{rpm})$ and $\mathrm{C}_{\mathrm{w}}=25 \%$. 
S. M. Selim, M. A. El-kadi, M. A. Younes, M. A. Hosien, and I. R. Teaima, "The Effect of Solid-Liquid ... ."

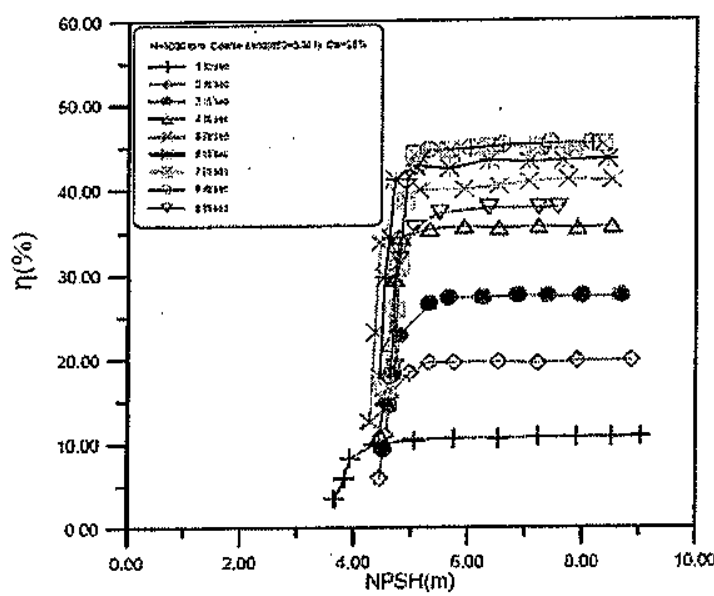

Fig.7 Variation of NPSH with pump efficiency for coarse sand $(\mathrm{d} 50=0.341 \mathrm{~mm})(\mathrm{N}=2900 \mathrm{rpm})$ and $\mathrm{C}_{\mathrm{w}}=25 \%$.

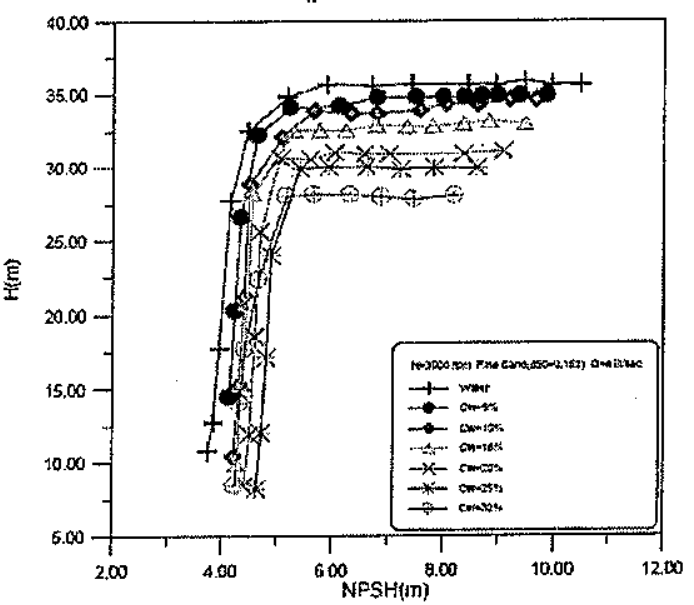

Fig.8 Variation of NPSH with purnp head at different solid concentration at constant speed $(\mathrm{N}=3000 \mathrm{rpm})$ for fine sand $\left(\mathrm{d}_{50}=0.152 \mathrm{~mm}\right)$ at $4 \mathrm{lit} / \mathrm{sec}$.

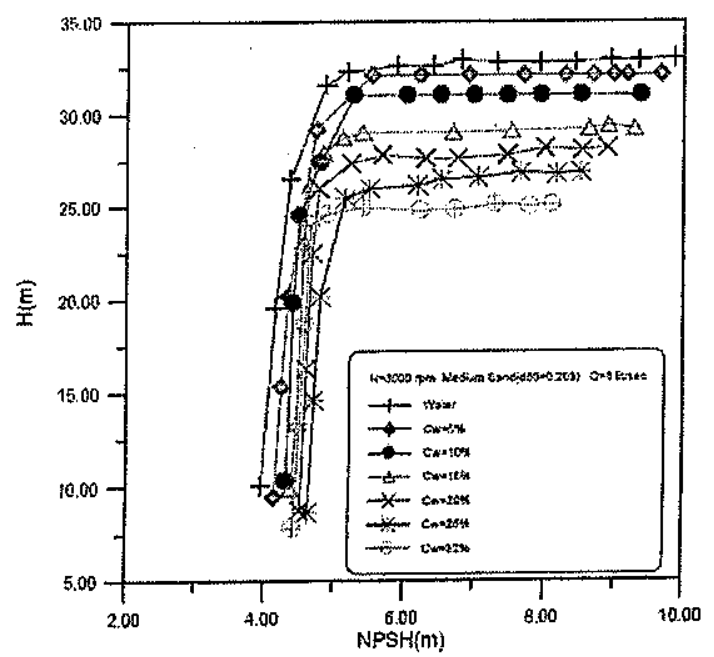

Fig.9 Variation of NPSH with pump head at different solid concentration at constant speed $(\mathrm{N}=3000 \mathrm{rpm})$ for medium sand $\left(d_{50}=0.203\right)$ at $6 \mathrm{lit} / \mathrm{sec}$.

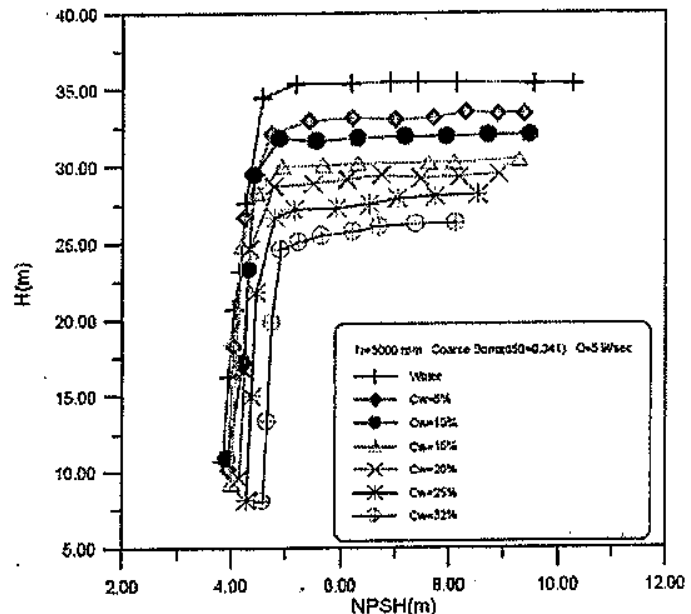

Fig.10 Variation of NPSH with pump head at different solid concentration at constant speed $(\mathrm{N}=3000 \mathrm{rpm})$ for coarse sand $\left(\mathrm{d}_{50}=0.341 \mathrm{~mm}\right)$ at 5 lit/sec.

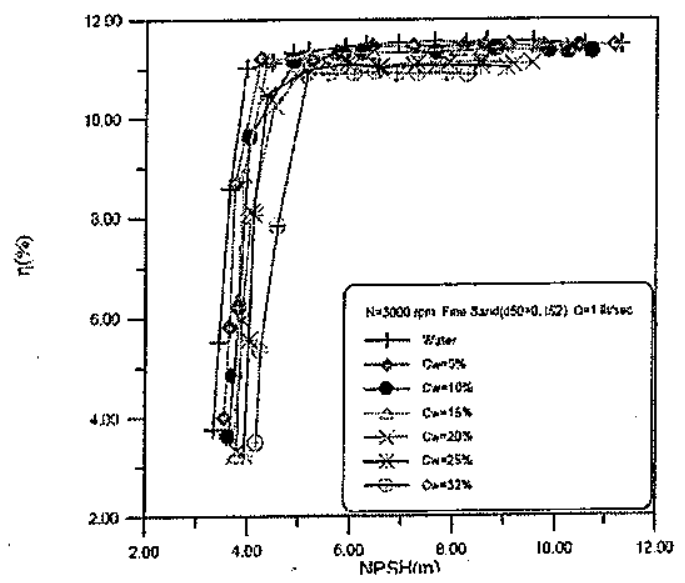

Fig.11 Variation of NPSH with pump efficiency at different solid concentration at constant speed $(\mathrm{N}=3000 \mathrm{rpm})$ for fine sand.$\left(\mathrm{d}_{50}=0.152 \mathrm{~mm}\right)$ at 1

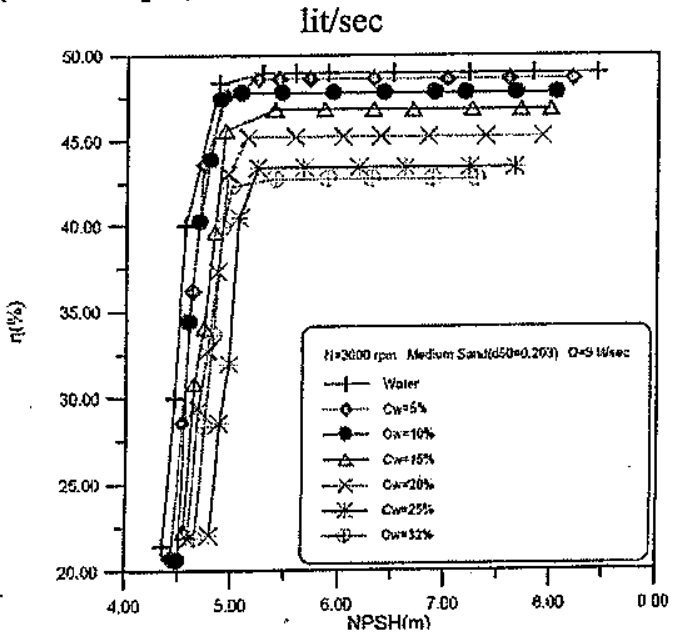

Fig.12 Variation of NPSH with pump efficiency at different solid concentration at constant speed $(\mathrm{N}=3000 \mathrm{rpm})$ for medium sand $\left(\mathrm{d}_{50}=0.203 \mathrm{~mm}\right)$ at 9 lit/sec. 
S. M. Selim, M. A. El-kadi, M. A. Younes, M. A. Hosien, and I. R. Teaima, "The Effect of Solid-Liquid ... "

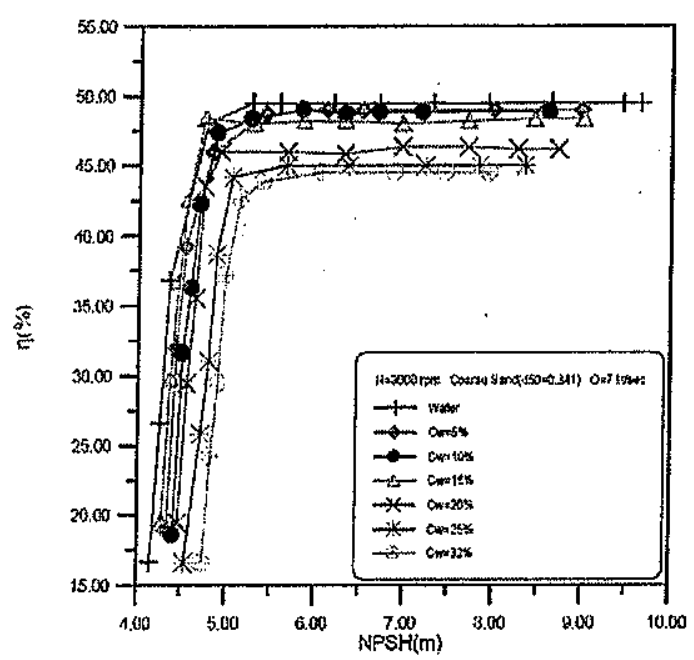

Fig.13 Variation of NPSH with pump efficiency at different solid concentration at constant speed

$(\mathrm{N}=3000 \mathrm{rpm})$ for coarse sand..$\left(\mathrm{d}_{50}=0.341 \mathrm{~mm}\right)$ at 8

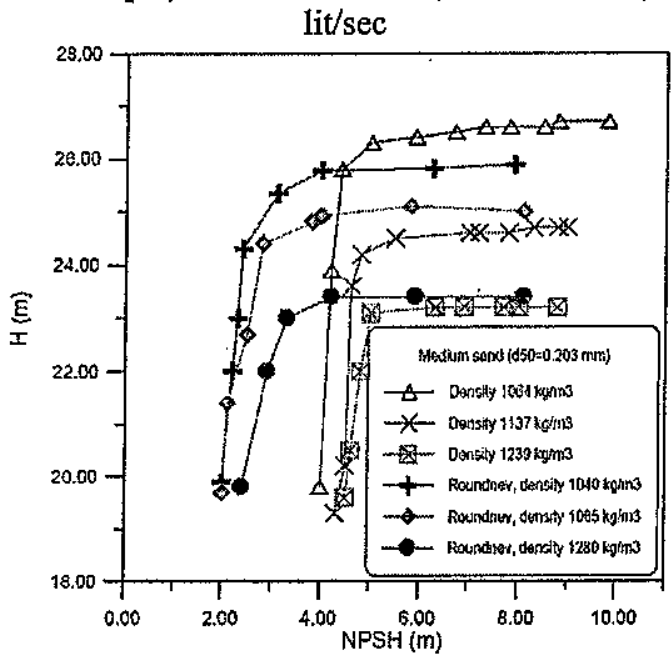

Fig.14 Comparison of the experimental results with Roundnev [1].

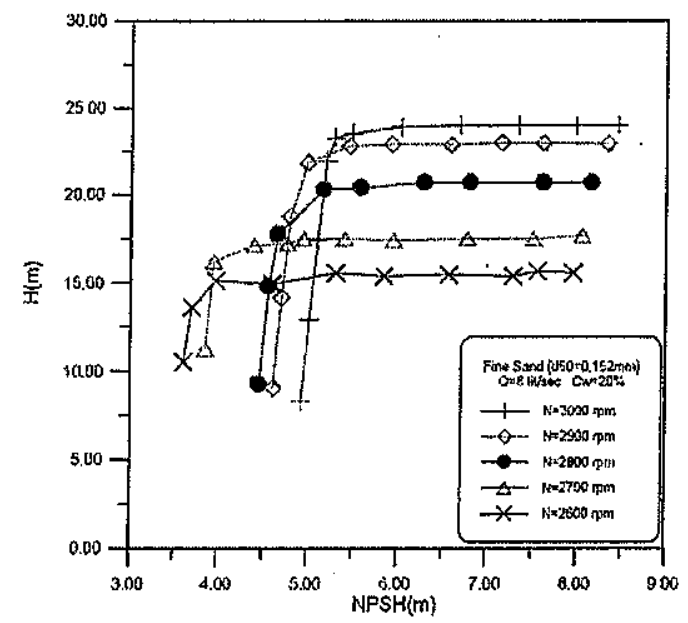

Fig.15 Variation of NPSH with pump head at different rotational speed for fine sand $\left(\mathrm{d}_{50}=0.152 \mathrm{~mm}\right)$ at $\mathrm{C}_{\mathrm{w}}=20 \%$ and $8 \mathrm{lit} / \mathrm{sec}$.

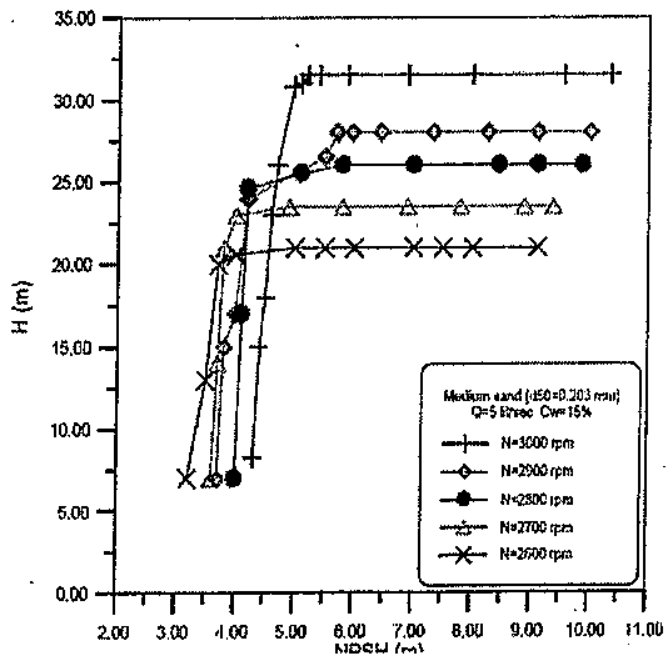

Fig.16 Variation of NPSH with pump head at different rotational speed for medium sand $\left(d_{50}=0.203 \mathrm{~mm}\right)$ at $\mathrm{C}_{\mathrm{w}}=15 \%$ and $5 \mathrm{lit} / \mathrm{sec}$.

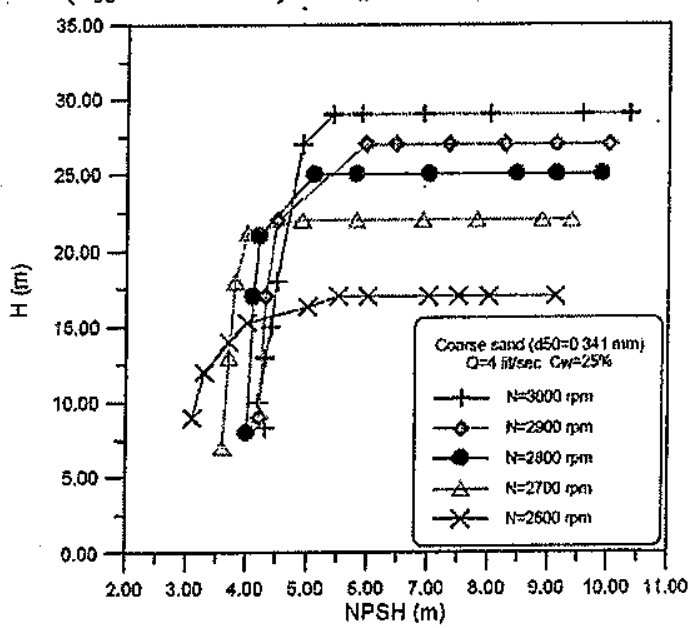

Fig.17 Variation of NPSH with pump head at different rotational speed for coarse sand $\left(\mathrm{d}_{50}=0.341\right.$ $\mathrm{mm}$ ) at $\mathrm{C}_{\mathrm{w}}=25 \%$ and $4 \mathrm{lit} / \mathrm{sec}$.

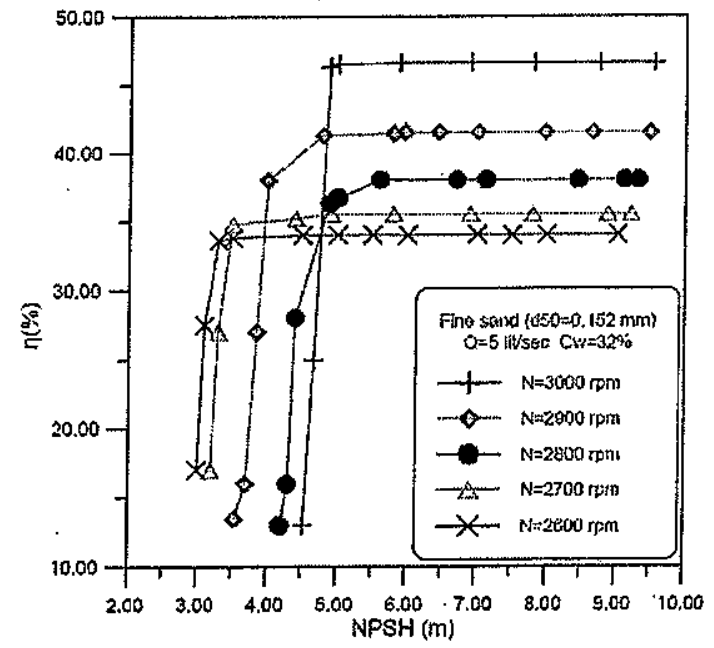

Fig.18 Variation of NPSH with pump efficiency at different rotational speeds at constant $Q$ and $C_{w}$. 
S. M. Selim, M. A. El-kadi, M. A. Younes, M. A. Hosien, and I. R. Teaima, "The Effect of Solid-Liquid ... "

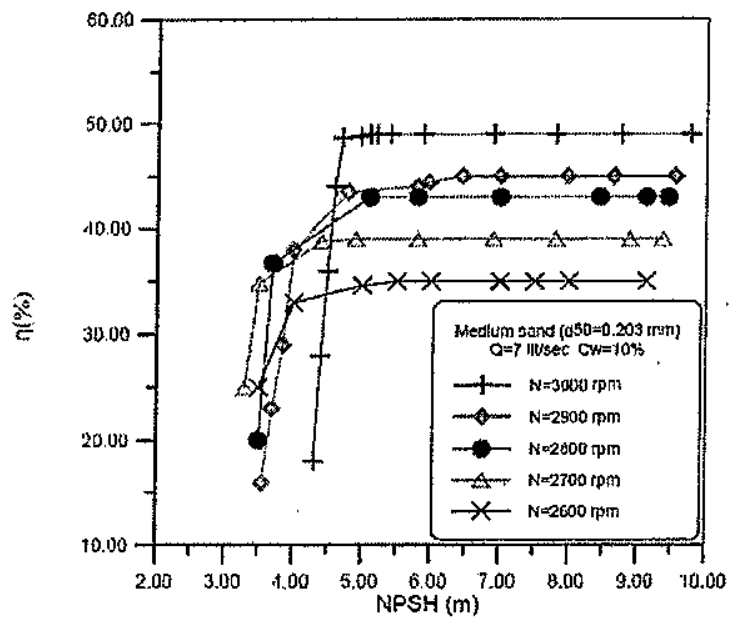

Fig.19 Variation of NPSH with pump efficiency at different rotational speeds at constant $Q$ and $C_{w}$.

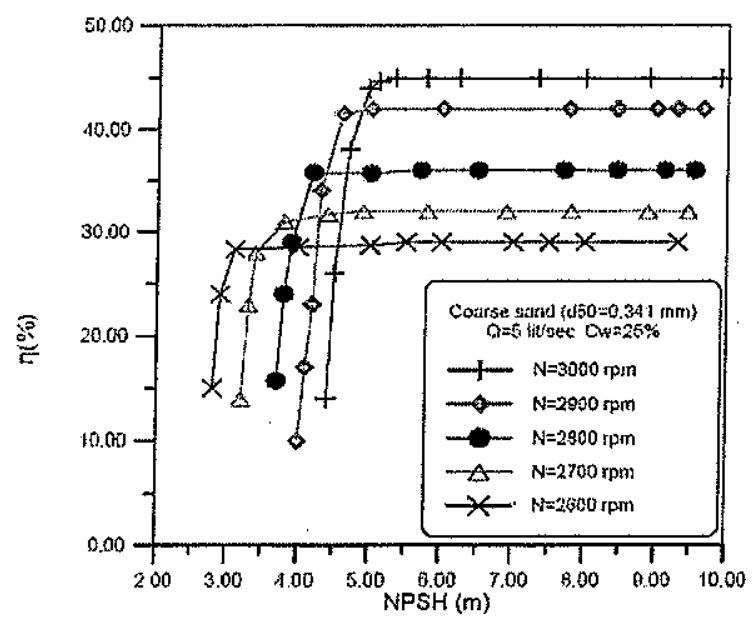

Fig.20 Variation of NPSH with pump efficiency at different rotational speeds at constant $Q$ and $C_{w}$.

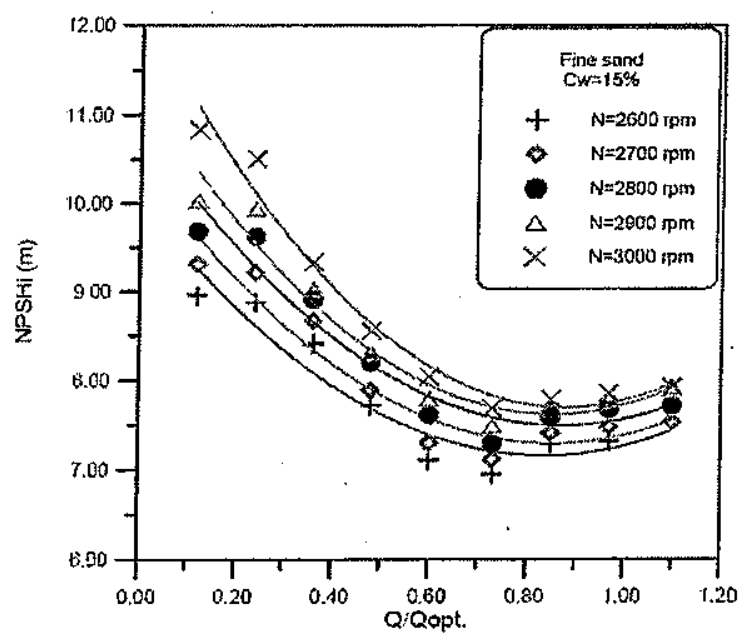

Fig.21 Variation of NPSH with flow rate ratio for fine sand at $\mathrm{C}_{\mathrm{w}}=15 \%$.

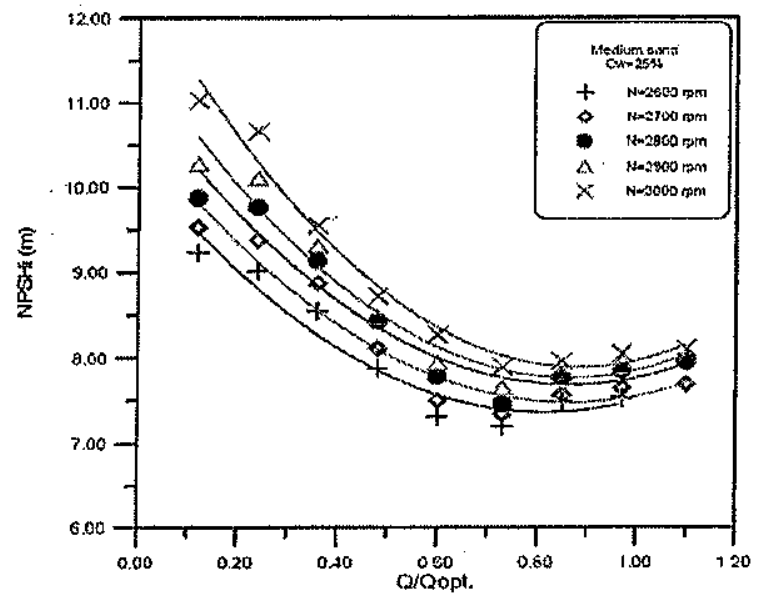

Fig.22 Variation of NPSH with flow rate ratio for medium sand at $\mathrm{C}_{\mathrm{w}}=25 \%$.

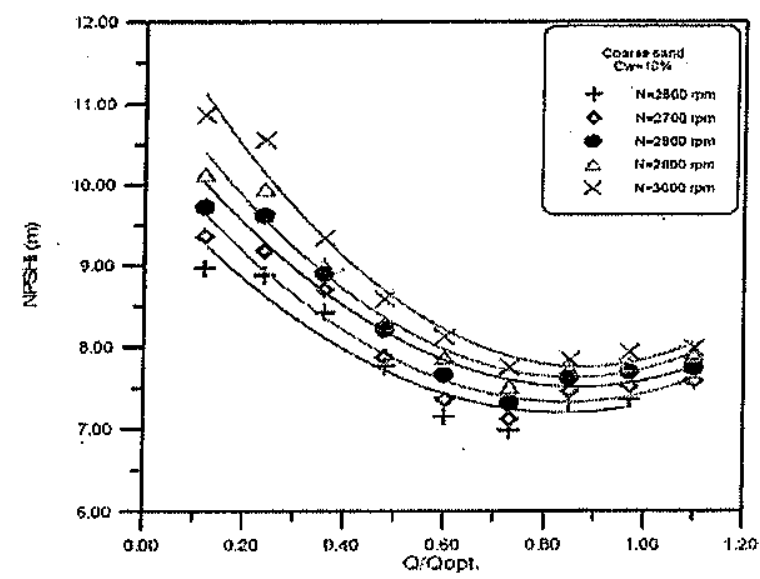

Fig.23 Variation of NPSH with flow rate ratio for coarse sand at $\mathrm{C}_{\mathrm{w}}=10 \%$.

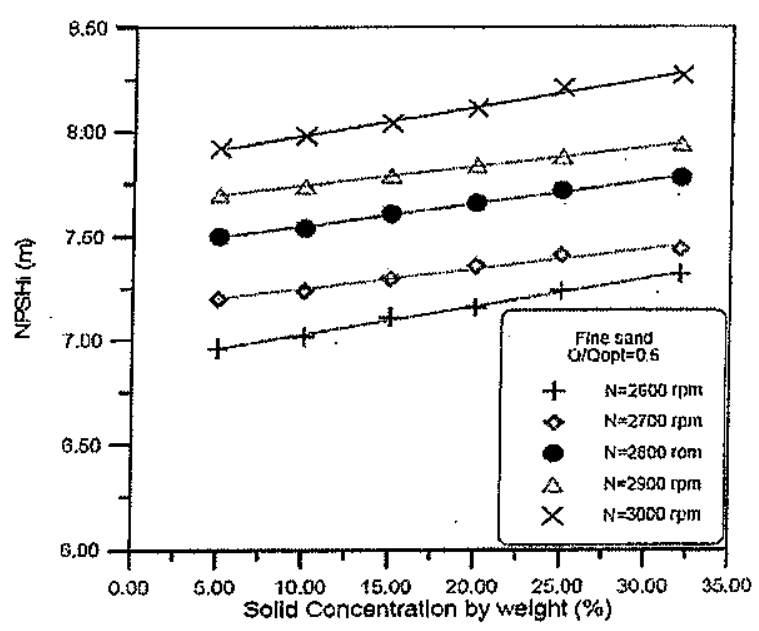

Fig.24 Variation of NPSH with solid concentration at varied rotational speed and $Q / Q_{\text {opt }}=0.6$ for fine sand. 
S. M. Selim, M. A. El-kadi. M. A. Younes, M. A. Hosien, and I. R. Teaima, "The Effect of Solid-Liquid ... "

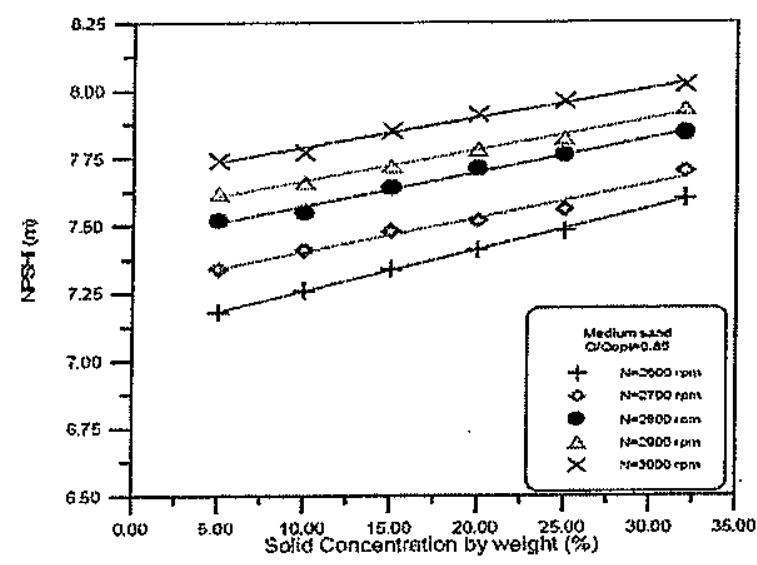

Fig.25 Variation of NPSH with solid concentration at varied rotational speed and $\mathrm{Q} / \mathrm{Q}_{\mathrm{opt}}=0.85$ for medium sand.

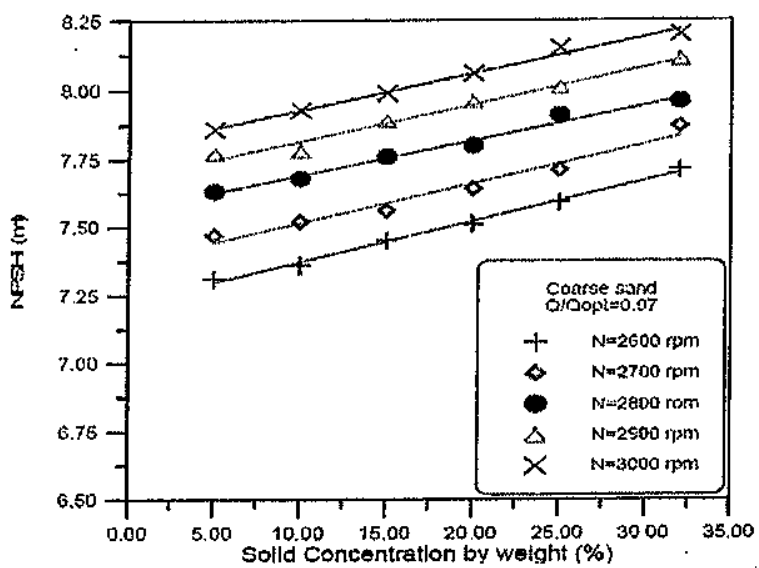

Fig.26 Variation of NPSH with solid concentration at varied rotational speed and $\mathrm{Q} / \mathrm{Q}_{\mathrm{opt}}=0.97$ for coarse sand.

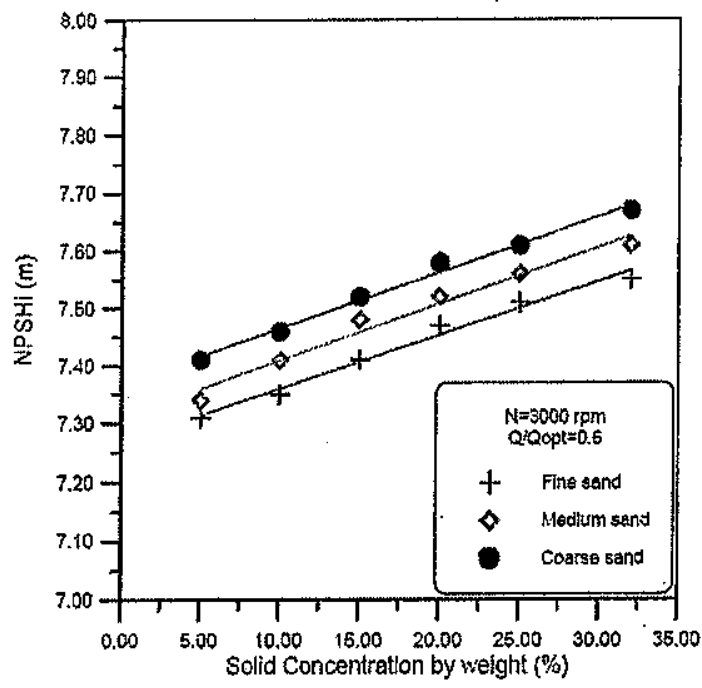

Fig.27 Variation of NPSHi with solid concentration at varied particle size with constant $\mathrm{N}$ and $\mathrm{Q} / \mathrm{Q}_{\mathrm{opt}}$

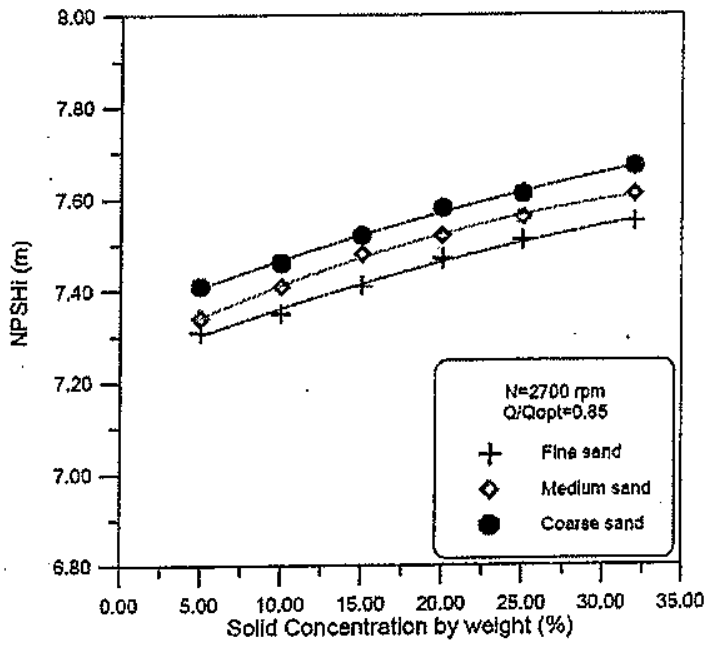

Fig.28 Variation of NPSHi with solid concentration at varied particle size with constant $N$ and $Q / Q_{\text {opt }}$.

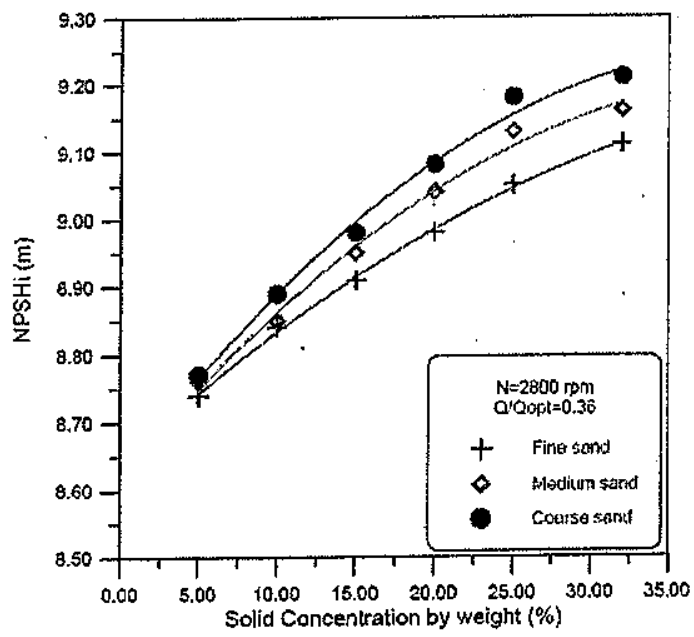

Fig.29 Variation of NPSHi with solid concentration at varied particle size with constant $N$ and $Q / Q_{o p . t}$.

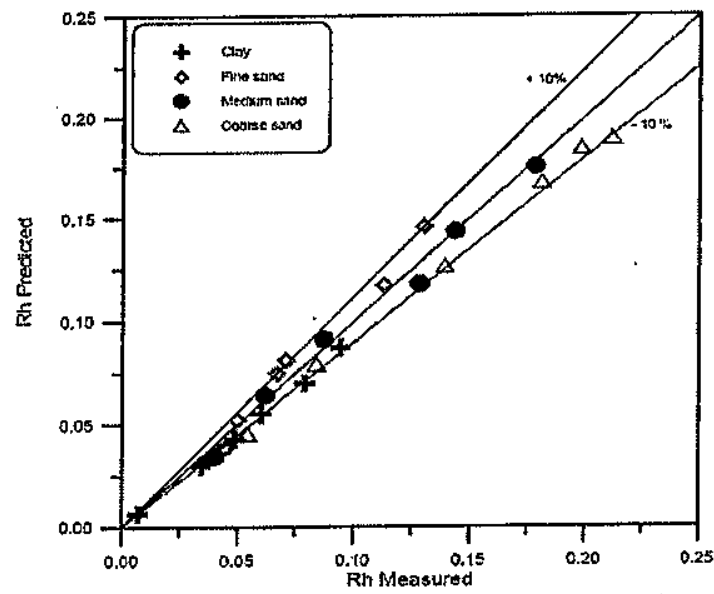

Fig.30 Comparison of measured and predicted $R_{h}$ using the proposed correlation. 